Keywords: Affect, Cognition, Emotion, Well-being, Discomfort, Empowerment.

\title{
Influence of affective personality on cognition-mediated emotional processing: Need for empowerment
}

\author{
Trevor Archer*, ** \\ Lillemor Adrianson ${ }^{\star \star \star}$ \\ Allen Plancak ${ }^{\star \star}$ \\ Erica Karlsson ${ }^{\star, \star \star}$ \\ * University of Kalmar, Department of \\ Health and Behavioral Science \\ ** University of Göteborg, Department of \\ Psychology \\ *** University of Borås, School of Education \\ and Behavioral Sciences
}

SWEDEN

\begin{abstract}
Background and Objectives: The notion that both positive and negative affect contribute not only to affective personality profiles but also to self-report estimations of both psychological and physical well-being or discomfort.

Method: Two studies are described, based upon applications of psychometric and clinical instruments, including the Positive Affective and Negative Affect Scale (PANAS), Stress and Energy (SE), Dispositional optimism (LOT), Locus of Control, Beck Depression Inventory (BDI), Perfectionism, Hospital Anxirty and Depression (HAD) and the Uppsala Sleep Inventory (USI). In Study 1, one hundred and twenty-two high school students (Gothenburg, Sweden), aged 17-19 years participated, whereas in Study 2, two hundred and eight professional office employees from a number of government agencies and corporations (Borås, Sweden), aged 27-61 years participated. Measures for HAD-anxiety and HAD-depression from five other studies of affective personality profiles were included also.

Results: The results indicated marked differences in both psychological and physical well-being or discomfort due to affective personality profiles, whereby "Self-fulfilling" individuals, expressing high positive affect and low negative affect, presented markedly better health profiles than the other three types of affective personality, i.e. "Low affective", "High affective" and "Self-destructive".

Conclusions: In this regard the notion of "empowerment" as a vehicle for putative reinforcements of cognitive abilities that modulate emotional systems is discussed.
\end{abstract}




\section{Introduction}

Affective state may be considered as the expression of the concatenation of feelings and emotions stemming from the outcome of individuals' appraisals, evaluations and decisions of the situationns and events the individuals are confronted with. The final outcome of an individual's evaluation of the immediate social/physical/occupational environment may be expressed in various behavioural forms some of which may be suitable to the situation/event, others may give an impression of normality and still others may express behavioural disturbances, generally in the shape of affective disorders characterised by disorder feelings and emotions that produce, in consequence, a plethora of maladaptive and self-defeating functional, or rather dysfunctional, expressions. To some extent, these affective problems may be heritable ${ }^{1,2}$, but for present purposes this review will focus almost exclusively upon the role of environmental, particularly social and occupational, influences in final common pathways of affect that individuals bring with them to daily events confronting them, and the suitability of coping measures available. Certainly, individual confrontation with stressful events remains a central issue ${ }^{3}$. It is clear that in addition to adverse effects on well-being and quality-of-life, situations associated with stress, anxiety, fatigue and depression pose potentially grave dangers for health ${ }^{4}$.

Individuals' particular responses to negative events are directly generally by situation profiles consisting of the sum total of a complex array of personal characteristics, including intellectual and cognitive abilities, emotional feelings as reflected by the relationship between positive and negative affect, originality and flexibility in problem-solving, degree of social support and contacts, and willingness to take personal risks. Affect refers to subjective moods and feelings, rather than thoughts concerning specific events ${ }^{5}$, and is intimately connected to feelings of depression, anxiety, fatigue, stress and 'burnout' ${ }^{6-8}$. Applications of these notions of affect render an individual's experience of stress as highly subjective with coping expressions perceived as homeostatic/transformational responses leading to either positive/negative outcome ${ }^{9}$. Depressive or anxious predispositions are likely to affect the outcome of personal trait measurements ${ }^{10,11}$. Thus, two basic factors, Positive Affect (PA) and Negative Affect (NA), have emerged as important dimensions of an individual's emotional experience ${ }^{12-14}$. The PA-NA self-estimates of affect evoke expressions of mood and ongoing feelings thereby corresponding to measures of personality and emotionality but also providing a probability against which aspects of cognitive performance may be assessed $^{15}$. Watson and co-workers have demonstrated repeatedly that NA is associated with measures of neuroticism and negative emotionality, as well as marked symptoms of stress $^{16-18}$. Conversely, PA expresses enthusiasm, activity, alertness, control, commitment and challenge ('hardiness'), with a general disposition towards a positive outlook and a satisfactory perception and appraisal of potentially stressful events ${ }^{19}$. Both PA and NA influence the manner and extent to which individuals view, experience and approach stressful events over both time and circumstance $^{20,21}$. High NA is associated with subjective complaints, poor coping and trait anxiety $^{22}$ whereas high PA is associated with sociability, control, helpful behaviour, feelings of duty, accuracy, care in decision-making and positive attitude over time and circumstance $^{23-25}$. Thus, high PA individuals experience a greater appreciation of life, more security, generally show more self-confidence ${ }^{26,27}$, more social relations and assertive- 
ness, greater satisfaction of friends, and are often described as passionate, happy, energetic and alert ${ }^{16,28}$; high NA individuals experience the reverse, greater stress, strain and cynicism in a wide range of circumstances and events of which they experience slight, if any, control ${ }^{23,29}$. Note that the contributions of positive upon expectancy motivation, cognitive functioning, clinical problem-solving, decision-making considerations, creative problem-solving, word associations and memory accessibility have all been documented, thereby underlining associations between affective state and cognitive processing $^{30}$.

\section{The Notion of Affective Personality}

Wilson et al $^{31}$ indicated that there existed no significant correlations between the PA and NA scales of the Positive Affect and Negative Affect scale (PANAS) under normal conditions. Furthermore, it has been shown, using functional magnetic resonance imaging, that high PA is associated with less mental efforts and greater efficacy in neural processing of working memory in demanding tasks ${ }^{32}$, implying a relationship between affect, cognition and brain functioning ${ }^{33}$. In this context, we have applied the notion of affective personality ${ }^{15}$, incorporating different combinations of high and low PA and NA: individuals expressing high PA and low NA ("Self-fulfilling" individuals), individuals expressing high PA and high NA ("High affective" individuals), individuals expressing low PA and low NA ("Low affective" individuals), and individuals expressing low PA and high NA ("Self-destructive" individuals). Self-fulfilling individuals displayed the highest levels of performance and expressed less stress than the other three types of affective personality. Recent studies ${ }^{34,35}$ have indicated that Self-fulfilling individuals presented a more psychologically healthy profile, pertaining to subjective stress, energy and stress, dispositional optimism, depression and anxiety, total stress at place of work, emotional stability and partner relationships, than individuals presenting a Self-destructive type of affective personality.

The purpose of the present study was to ascertain the influence of affective personality behaviour-profiles upon expressions of cognitive-emotional estimations of health, personal resources and expectancies, as reflected by self-reports of affect, stress experience, optimism, quality of sleep, extent of depressiveness and tendency towards internal/external expectancies. Personal outlook and individuals' cognitive-emotional functionality within the sphere of daily living may be depicted from the results of two unpublished studies carried out recently [MarchApril, 2006], under supervision at the Department of Psychology, Göteborgs University.

\section{Methods}

\section{Participants}

Study 1. One hundred and twenty-two high school students (Gothenburg, Sweden), aged 17-19 years participated. Each participant was asked to complete a battery of psychometric test instruments including PANAS, Energy and Stress, Dispositional optimism, the Uppsala Sleep Inventory, Locus of Control, and Beck's Depression Inventory (BDI).

Study 2. Two hundred and eight professional office employees from a number of government agencies and corporations 
(Borås, Sweden), aged 27-61 years participated. Of these employees, seventy-three held leadership positions and one hundred and thirty-five were part of the work groups. Each participant was asked to complete a battery of psychometric test instruments including PANAS, Energy and Stress, Dispositional optimism, Locus of Control, and Perfectionism.

Studies I-V. Populations ranging from N $=73$ to $\mathrm{N}=238$, described previously, in five different studies performed on student or occupational populations ${ }^{22,33}$. Each participant was asked to complete a battery of psychometric test instruments including PANAS and Hospital Anxiety and Depression Scales (HAD).

\section{Instruments}

Positive affect and negative affect scale (PANAS). The PANAS-instrument provides a self-estimation of "affect", both positive and negative. It consists of 10 adjectives for the NA dimension and 10 adjectives for the PA dimension. The test manual ${ }^{17}$ postulates that the adjectives describe feelings (Affect) and mood level. Participants were instructed to estimate how they felt during the last few days. The response alternatives were presented on a five-grade scale that extended from where ' 1 ' = "not at all" to ' 5 ' = "very much". For each participant the responses to the 10 negatively-charged adjectives were summated to provide a total NA-result for NA affect, and similarly the responses to the positively-adjectives were summated to provide a total PA-result for PA affect. The PANAS instrument has been validated through studies analyzing conditions associated with general aspects of psychopathology, as well as a multitude of other expressions of affect ${ }^{16}$. Previous stud- ies $^{15,33,35}$ have modified and developed the PANAS instrument further through a subject-response based derivation of the four types of affective personality (see Design). This procedure was implemented in the present study through dividing the results on the PA-scale into two parts thereby distributing the participants into one group with high PA and another group with low PA (cut-off point $=53.2 \%$ ). The same procedure was implemented for the participants' responses on the NA-scale (cut-off point $=48.9 \%$ ). Following this, the results from these two scales were combined according to the procedure that assigned each one of the participants into one of the four affective personality groups, as follows: individuals showing high PA and low NA ("Self-fulfilling"), high PA and high NA ("High affective"), low PA and low NA ("Low affective") and low PA and high NA ("Self-destructive").

Stress and Energy (SE). The SE-instrument is a self-estimation scale, consisting of 12 items, that assesses individuals' experience of their own stress and energy ${ }^{36}$. The test is divided into two sub-scales that express each participant's level of mood in the two dimensions: "experienced stress" and “experienced energy". Response alternatives are ordered within six-graded scales that extend from ' 0 ' = "not at all" to ' 5 ' = "very much". The instrument has been validated through studies concerning occupational burdens and pressures.

Life orientation Test (LOT). The LOTinstrument is a self-estimation instrument that assesses an individual's degree of dispositional optimism. The instrument is based on a general model, regarding self-regulated behaviour, that indicates that optimism exerts meaningful behavioural consequences based on the model. It was constructed originally to study the extent to which the personality trait 
optimism was associated with the ability to develop suitable 'coping strategies' in connection with severe psychological and physical handicaps (e.g. tinnitus) and predicting success-rate in physically demanding and stressful sports ${ }^{37}$, it was considered both sufficient and necessary for inclusion in the present study. The instrument consists of 12 statements from which each participant is instructed to assess the extent to which each of these statements fits in with him/her as an individual. The response alternatives are presented on a five-graded scale extending from ' 0 ' = "strongly disagree" to '4' = "strongly agree". LOT is a suitable scientific instrument with an estimated internal consistency of 0.76 (Cronbach's alpha) and a Test-Retest reliability of 0.79 (Pearson's $r$ ), indicating that the test result is stable over time. The LOT test requires about 5 minutes for completion.

Locus of Control. Locus of Control was measured using a modified version according to Millet and Sandberg ${ }^{38}$ using an abbreviated version of the Rotter scale ${ }^{39}$ as developed for use mainly in Swedish work settings. The scale has a minimum score of 8 and a maximum of 40 , with a lower score representing an external locus of control orientation and a higher score representing an internal locus of control orientation. Several empirical studies have shown that perceived control is strongly correlated with rehabilitational outcomes, not least empowerment ${ }^{40}$.

Beck's Depression Inventory (BDI). The original version was introduced by Beck et $a l .{ }^{41}$. The BDI is a 21 -item self-report rating inventory measuring characteristic attitudes and symptoms of depression. A high level of correlation has been found between the original and revised versions. Internal consistency for the BDI ranges from 0.73 to 0.92 with a mean of $0.86^{42}$, with alpha coefficients of 0.86 and 0.81 for psychiatric and non-psy- chiatric populations, respectively. Correlations with clinician ratings of depression, using the revised BDI, range from 0.62 to $0.66^{43}$.

Perfectionism. Perfectionism was measured according to Flett and Hewitt's ${ }^{44}$ Perfectionism and Attitudes Scales (PAS), as modified and translated for Swedish applications. The instrument consists of 33 statements that cover 'self-oriented perfectionism (a predisposition to set high standards for oneself), socially-prescribed perfectionism (a tendency to believe that others make great demands upon oneself) and other-oriented perfectionism (a tendency to make heavy demands upon other individuals). The answers are coded on a 5-point Likert scale (' 1 ' = "not at all true", '5' = "true"), whereby higher scores represent more perfectionism, as outlined by Agerström et al. ${ }^{34}$ who have found an internal reliability (Cronbach's alpha) of 0.88 .

Hospital Anxiety and Depression (HAD). HAD provides a reliable and valid self-estimation instrument that assesses an individual's degree of anxiety and depression ${ }^{45}$. The instrument consists of 12 statements, each followed by four response alternative from which the participant is instructed to mark the appropriate one. The alternatives include: "most often", "often", "now and then" and "not ever". Summated response values under 6 are considered normal, values between 6 and 10 indicate a border level while values above 10 indicate a probable anxiety and/or depression diagnosis.

Uppsala Sleep Inventory (USI). The USI is a self-report instrument describing participants' sleep profiles ${ }^{46}$, as characterised by descriptions of potential difficulties falling asleep, psychophysiological problems (such as bodyaches, muscle tension, beating heart, 'pins-and-needles', anxiety feelings, etc.) 
and larger sleep problems ${ }^{47}$. An example of a question is: "Do you have a great problem falling asleep at night?" Here five response alternatives were available: "none", "a little", "about average", "large" and "very great".

Procedure. Participants were assembled in groups of 5-10. They were given an envelope containing the questionnaire with all the instruments and were instructed to complete these quietly and independently. All instructions and questionnaires were in Swedish and the participants were guaranteed anonymity. First, the participants completed a background sheet providing information concerning age, sex, education, physical exercise, use of medicine, etc. After this, they completed all the other instruments, including PANAS, SE, LOT,
Locus of Control, BDI, Perfectionism and USI.

\section{Results}

\section{Study 1}

"Self-fulfilling" individuals reported significantly more energy and optimism than "Self-destructive", "High affective" and "Low affective" individuals. Concurrently, "Self-fulfilling" individuals reported significantly less stress, fewer sleep problems, less inability to fall asleep, fewer psychophysiological problems, lesser External locus of control and a lower sum of depressive symptoms accordinng to the BDI (for One-way ANOVA values, as well as means and standard deviations, see Table I).

Table I

Self-reported levels of Energy and Stress, Optimism, Sleep problems, Problems assciated with falling asleep, Psychophysiological problems, External Locus of control and Sum of BDI by participants [High School students, aged 17-19 years] categorised as possessing "Self-fulfilling", "High affective", "Low affective" or "Self-destructive" types of affective personality, as indexed by PANAS ${ }^{22}$.

\begin{tabular}{|c|c|c|c|c|}
\hline & $\begin{array}{l}\text { "Self-fulfilling" } \\
\quad(\mathrm{n}=32)\end{array}$ & $\begin{array}{l}\text { "High affective" } \\
\quad(\mathrm{n}=30)\end{array}$ & $\begin{array}{l}\text { "Low affective" } \\
\qquad(\mathrm{n}=31)\end{array}$ & $\begin{array}{l}\text { "Self-destructive" } \\
(\mathrm{n}=29)\end{array}$ \\
\hline $\begin{array}{l}\text { Energy } \\
{[\mathrm{F}(3,118)=6.08, \mathrm{p}<0.001]}\end{array}$ & $3.03 \pm 0.88 *$ & $3.02 \pm 0.79$ & $2.44 \pm 0.75$ & $2.35 \pm 0.66$ \\
\hline $\begin{array}{l}\text { Stress } \\
{[\mathrm{F}(3,118)=6.99, \mathrm{p}<0.001]}\end{array}$ & $1.57 \pm 0.90 *$ & $2.67 \pm 1.14$ & $2.16 \pm 0.75$ & $2.80 \pm 1.06$ \\
\hline $\begin{array}{l}\text { Optimism } \\
{[\mathrm{F}(3,118)=11.00, \mathrm{p}<0.001]}\end{array}$ & $2.73 \pm 0.45^{*}$ & $2.30 \pm 0.65$ & $2.32 \pm 0.35$ & $1.88 \pm 0.62$ \\
\hline $\begin{array}{l}\text { Sleep problems } \\
{[\mathrm{F}(3,118)=4.92, \mathrm{p}<0.001]}\end{array}$ & $14.81 \pm 3.85^{*}$ & $17.13 \pm 4.35$ & $16.64 \pm 3.88^{*}$ & $19.55 \pm 4.77$ \\
\hline $\begin{array}{l}\text { Inability to sleep }{ }^{1} \\
{[\mathrm{~F}(3,118)=4.83, \mathrm{p}<0.001]}\end{array}$ & $16.78 \pm 2.99 *$ & $20.87 \pm 6.99$ & $19.03 \pm 4.80^{*}$ & $23.90 \pm 4.67$ \\
\hline $\begin{array}{l}\text { Psychophysiol. } \\
{[\mathrm{F}(3,118)=4.69, \mathrm{p}<0.001]}\end{array}$ & $6.09 \pm 1.38^{*}$ & $8.43 \pm 3.30$ & $6.52 \pm 2.20 *$ & $9.52 \pm 3.84$ \\
\hline $\begin{array}{l}\text { External LOC } \\
{[\mathrm{F}(3,118)=3.61, \mathrm{p}<0.001]}\end{array}$ & $9.65 \pm 2.16^{*}$ & $11.13 \pm 2.70$ & $10.42 \pm 1.82$ & $11.52 \pm 2.75$ \\
\hline $\begin{array}{l}\text { Sum of } \mathrm{BDI}^{4} \\
{[\mathrm{~F}(3,118)=9.03, \mathrm{p}<0.001]}\end{array}$ & $4.65 \pm 3.91 *$ & $10.90 \pm 9.44$ & $7.39 \pm 7.36^{*}$ & $18.62 \pm 12.07$ \\
\hline
\end{tabular}

\footnotetext{
${ }^{1}$ Problems associated with falling asleep.

2 Psychophysiological problems.

${ }^{3}$ External Locus of control.

${ }^{4} \mathrm{BDI}=$ Beck Depression Inventory [summated over all items].

* $p<0.01$, versus "Self-destructive" group, Tukey HSD-testing.
} 


\section{Study 2}

"Self-fulfilling" individuals reported significantly more energy and optimism than "Self-destructive", "High affective" and "Low affective" individuals. Concurrently, "Self-fulfilling" individuals reported significantly less stress, less perfectionism and lesser External locus of control (for One- way ANOVA values, as well as means and standard deviations, see Table II).

Table III summarises the findings from five different studies all included selfreports upon the PANAS and HAD instruments. It is evident that the "Self-fulfilling" individuals invariably express significantly less anxiety and depression than "Self-

Table II

Self-reported levels of Energy and Stress, Optimism, Perfectionism, Internal Locus of control and External Locus of control [White collar professional employees, aged 27-61 years] categorised as possessing "Selffulfilling", "High affective", "Low affective" or "Self-destructive" types of affective personality, as indexed by PANAS 22 .

\begin{tabular}{lccrc} 
& $\begin{array}{c}\text { "Self-fulfilling" } \\
(\mathrm{n}=61)\end{array}$ & $\begin{array}{c}\text { "High affective" } \\
(\mathrm{n}=48)\end{array}$ & $\begin{array}{c}\text { "Low affective" } \\
(\mathrm{n}=52)\end{array}$ & $\begin{array}{c}\text { "Self-destructive" } \\
(\mathrm{n}=47)\end{array}$ \\
\hline Energy & $3.79 \pm 0.61^{*}$ & $3.34 \pm 0.88$ & $3.03 \pm 0.89$ & $3.14 \pm 0.77$ \\
Stress & $1.26 \pm 0.60^{*}$ & $1.58 \pm 0.74$ & $1.57 \pm 0.85$ & $2.02 \pm 0.84$ \\
Optimism & $3.07 \pm 0.37 *$ & $2.82 \pm 0.52$ & $2.71 \pm 0.40$ & $2.57 \pm 0.51$ \\
Perfectionism & $8.80 \pm 1.37 *$ & $10.23 \pm 1.79$ & $9.52 \pm 1.32$ & $10.14 \pm 1.33$ \\
Internal LOC $^{2}$ & $12.89 \pm 2.99$ & $12.71 \pm 2.57$ & $12.46 \pm 2.53$ & $12.20 \pm 2.34$ \\
External LOC & $9.31 \pm 2.41^{3}$ & $10.27 \pm 2.70$ & $10.27 \pm 2.56$ & $10.37 \pm 2.62$ \\
\hline
\end{tabular}

${ }^{1}$ Perfectionism and Attitudes Scales.

${ }^{2}$ Internal Locus of control.

${ }^{3}$ External Locus of control.

$\mathrm{p}<0.05$, versus "Self-destructive" group, Tukey HSD-testing.

Table III

Influence of type of affective personality upon responses to the Hospital Anxiety and Depression (HAD) Scale. Self-reported levels of HAD-anxiety and HAD-depression by participants categorised as "Selffulfilling", "High affective", "Low affective" or "Self-destructive" according to self-estimated responses to PANAS in five different studies performed on student or occupational populations ${ }^{22,33}$.

\begin{tabular}{|c|c|c|c|c|c|}
\hline & Study I & Study II & Study III & Study IV & Study V \\
\hline Participants (N) & 73 & 91 & 139 & 217 & 238 \\
\hline Age of participants & $25.3( \pm 4.5)$ & $17.4( \pm 1.0)$ & $34.6( \pm 6.6)$ & $17.4( \pm 1.6)$ & $18.2( \pm 1.2)$ \\
\hline Occupation & Working & Student & Working & Student & Student \\
\hline \multicolumn{6}{|l|}{ HAD-anxiety } \\
\hline Self-fulfilling & $3.76 \pm 3.03$ & $4.48 \pm 1.95$ & $3.12 \pm 2.06$ & $3.34 \pm 2.07$ & $3.97 \pm 1.86$ \\
\hline High affective & $6.63 \pm 3.30 *$ & $8.29 \pm 3.75^{*}$ & $7.74 \pm 1.45^{*}$ & $8.43 \pm 1.84 *$ & $9.35 \pm 2.95 *$ \\
\hline Low affective & $5.68 \pm 2.49^{*}$ & $5.54 \pm 2.33^{*}$ & $4.30 \pm 1.92$ & $6.99 \pm 2.28^{*}$ & $5.89 \pm 2.16^{*}$ \\
\hline Self-destructive & $11.00 \pm 2.91 *$ & $10.91 \pm 3.43^{*}$ & $8.28 \pm 3.30^{*}$ & $12.39 \pm 3.77 *$ & $12.77 \pm 3.11 *$ \\
\hline \multicolumn{6}{|l|}{ HAD-depression } \\
\hline Self-fulfilling & $1.94 \pm 1.74$ & $2.53 \pm 1.81$ & $1.74 \pm 1.45$ & $1.82 \pm 1.31$ & $1.79 \pm 1.04$ \\
\hline High affective & $2.63 \pm 2.43$ & $3.42 \pm 2.67$ & $3.31 \pm 1.99$ & $3.98 \pm 1.85^{*}$ & $3.67 \pm 1.53^{*}$ \\
\hline Low affective & $2.79 \pm 1.80$ & $2.77 \pm 1.83$ & $2.59 \pm 1.31$ & $3.27 \pm 1.54$ & $3.55 \pm 1.73 *$ \\
\hline Self-destructive & $6.11 \pm 2.74 *$ & $6.43 \pm 3.15^{*}$ & $5.24 \pm 2.89 *$ & $7.06 \pm 2.00 *$ & $7.39 \pm 3.09 *$ \\
\hline
\end{tabular}

*p $<0.01$, versus the "Self-fulfilling" groups Tukey HSD-testing. 
destructive" individuals, and generally less anxiety and depression than the "High affective" individuals. "Low affective" individuals appear to express, variably, more anxiety and depression than the "Self-fulfilling" individuals but somewhat less than the "High affective" individuals.

\section{Discussion}

Preliminary to the discussion of the main findings from the studies included, current notions pertaining to cognitive-emotional interactions and empowerment as a health care intervention are outlined.

\section{Neurocognitive influence upon emotional expression}

Despite the paucity of sufficient consideration of conscious emotional experience and affective states, several neuropsychological processes may be associated with discrete brain regions that influence the assimilation and analysis of incoming sensory information on the basis of emotional content and cognitive appraisal. Regional-functional processing includes several dominating brain influences: the role of the prefrontal cortex (PFC) and anterior cingulate gyrus in executive functioning and working memory, input of the amygdala into working memory, the mobilization of cortical arousal as a consequence of amygdala signalling and the information bestowed by feedback signalling from various parts of the body ${ }^{48,49}$. Cognitive influences upon the regulation of emotional processing ${ }^{50}$ underly much of the outcome expressed by affect, coping behaviour and the final common pathway resulting from personal empowerment. The ability to regulate emotional states remains a critical component of adaptive social functioning with profound consequences for internal states and expressed behaviours and actions. Thus, mechanisms of emotion and cognition appear to be intertwinned from early perception to reasoning such that the regional considerations of emotional expressions ${ }^{51}$ provide a template for the cognitive processing of those emotions ${ }^{52}$.

There appears some evidence to support the notion that positive and negative mood states affect cognitive functioning ${ }^{53}$, and the influence of neural systems upon executive functioning ${ }^{54}$. It would seem that mild manipulations of negative affect induce limted effects upon cognitive control processes whereas positive mood impairs aspects of planning and working memory ${ }^{55,56}$, but enhances performance on tasks of fluency and/or creativity ${ }^{57}$. In this context, evidence suggests that positive and negative mood/ affect are mediated differently in the brain ${ }^{58}$.

The inverse association between cognitive functioning and states of extreme affectemotion, such as depression and anxiety, has been observed repeatedly in both young and old populations ${ }^{59,60}$. Certain populationbased studies applying neurocognitive testing have indicated that higher levels of depressive symptoms are linked to performance deteriorations for measures of attention, memory, and concept formation ${ }^{61}$. Recently, Biringer et al. ${ }^{62}$ assessed the association between depression and/or anxiety, using the HAD instrument ${ }^{45}$, and cognitive performance, using the Digit Symbol test from WAIS-R, the Kendrick Object Learning test and the Controlled Oral Word Association test in 1930 elderly (72-74 years) non-demented patients. They obtained a significant association between depression, but not anxiety (an inverse association between anxiety and reduced cognitive performance 
was explained by adjustment for co-morbid depression), and reduced cognitive functioning, particularly on the Digit Symbol test and the Kendrick Object Learning test. It was found too that the male participants' cognitive performance was more adversely affected by depression than the female participants' performance. Against this context of an inverse relationship between cognition and depression-anxiety as estimated by the HAD instrument, it should be noted that even in healthy volunteers derived from wide-ranging age groups, the self-reported levels of anxiety and depression vary enormously between the four types of affective personality (see Table III). As evident, "Selfdestructive" individuals expressed markedly higher levels of both anxiety and depression than the individuals expressing a "Self-fulfilling" type of affective personality. It ought to be observed too that individuals expressing a "High affective" or "Low affective" type of affective personality evidenced too significantly higher levels of HAD-anxiety than the "Self-fulfilling" individuals in all five studies, but only evidenced significantly more HAD-depression in the fifth study (Study V). On the other hand, the "High affective" and "Low affective" individuals expressed both less HAD-anxiety and HADdepression than the "Self-destructive" individuals. These five studies, taken together, illustrate clearly that type of affective personality is linked to either lower ("Self-fulfilling") or higher levels ("Self-destructive") of affective disorder. Several factors may be considered to contribute to this situation: (i) "Self-fulfilling" individuals expressed significantly more emotional stability and personal responsibility than "Self-destructive" individuals ${ }^{22}$. (ii) "Self-fulfilling" individuals expressed significantly more energy and significantly less stress than "Self-destructive" individuals ${ }^{22,33}$. (iii) "Self-fulfilling" individuals expressed significantly less psychologi- cal stress, somatic stress and total stress at work than "Self-destructive" individuals ${ }^{22}$. (iv) "Self-fulfilling" individuals expressed significantly more beneficial personal relations and greater vigor than "Self-destructive" individuals ${ }^{22}$. (v) "Self-fulfilling" individuals expressed significantly more cognitive, emotional, social, physical, spiritual and total coping behaviour than "Selfdestructive" individuals ${ }^{22}$. (vi) "Self-fulfilling" individuals invariably expressed significantly more optimism than "Selfdestructive" individuals ${ }^{22,33}$. (vii) "Self-fulfilling" individuals expressed significantly higher levels of communication and superior partnership relations than "Self-destructive" individuals. (viii) "Self-fulfilling" individuals expressed a significantly higher degree of morality in terms of self-reported justice than "Self-destructive" individuals ${ }^{34}$.

\section{The Notion of Empowerment}

The notion of empowerment refers to an 'enabling' process that arises from a mutual sharing of resources and opportunities in order to enhance decision-making and cognitive processing to 'enable', facilitate and achieve positive changes at individual, congregational and community levels ${ }^{63}$. Empowerment has become a desirable goal for health care services whereby health is seen to be a fundamental human right along with participation and implementation of health care ${ }^{64}$. Empowerment, a multidimensional process, involves the attainment of individuals' control over their own lives ${ }^{65}$. For example, recently Weis et al. ${ }^{63}$ showed in a study involving parish nurse empowerment and client empowerment that empowerment is a reciprocal process between the parish nurse and client characterised by the recognition of a higher power, in this case the spiritual dimension. Empowerment has been employed 
by clinicians to 'empower' individuals with learning difficulties thereby optimising both resilience and self-advocacy, as well as health care efficacy ${ }^{65}$. Finally, an examination of sixty women with Borderline personality disorder and thirty women with social phobia indicated self-judgements strongly associated with low levels of both self-esteem and empowerment ${ }^{66}$.

It would appear that the "Self-fulfilling" individuals have acquired certain necessary characteristics that have rendered them 'resistent' to the damaging influences of stress, anxiety and depression in comparison with the other types of affective personality, and in particular, the "Self-destructive" individuals. Nevertheless, there is neither any mystery nor any secret formula that precludes individuals from acquiring this type of 'affective resistence'. The principle of 'empowerment' may be described according to several different perspectives, such as for example in the case where enlightened leadership delegates informed responsibility to those lower in hierarchy. Within the perspective cognitive functioning in the adaptational control of emotional expression, the term 'empowerment' is used to depict the influence of cognitive development in equiping individuals to experience events and express behaviour that consists of superior adaptive content. Several tactics/strategies are available for application: (a) Individuals may undergo training (in some cases therapy) that develop an awareness and ability to perceive problem-oriented, emotion-focussed and social network based coping strategies. Each of these coping strategies endowers a degree of empowerment. (b) Each potential stressor/trauma/catastrophe calls forth a series of primary, secondary and tertiary cognitive appraisals; individuals' physiologic and behavioural responses in different situations are directly by the results of these cognitive appraisals. The accurate assessment of situations derived from reliable cognitive appraisals may be acquired only through conscious experience aided by educational programs. (c) Personal characteristics contribute to a marked degree the outcome of appraisal, physiologic and behavioural incursions and the applications of affective personality and other personality instruments suggest that there is quite a substantial degree of consistency of personal characteristics over longer periods. 'Hardiness' coaching provides essentially a special form of empowerment, incorporating Control, Committment and Challenge. Thus, individuals may be trained to take steps to ensure control of uncertain situations, to committ sufficient resources to handling oncoming events and to view potentially stressful or hazardous situations/encounters as challenges. Individual empowerment presupposes the explicit application of personal resources, requiring conscious cognitive training techniques, to develop both general and specific patterns of behaviour that over repetition and application are rendered skilled behavioural programs requiring no more than an implicit and unconscious elicitations in the prescribed circumstances, for example, at a basic level through daily physical exercise and training programs ${ }^{67}$.

It is not surprising then that the outcome of emotional instigation and cognitive functioning regional brain interactive processes has been the focus of both research and theoretical notions ${ }^{68}$. It appears reasonable to assume that the notion postulating that the brain circuits underlying emotion and cognition may be integrated to produse a configuration consisting of four different processing 'matrices'. Accordingly, one of these may be assumed to mediate automated (unconscious, implicit) processing, one to mediate controlled (conscious, explicit) 
processing whereas the two remaining 'matrices' may be assumed to mediate interactive processing ${ }^{69}$. Expressions of behaviour are assumed to be activated selectively by one or a couple of the four processing 'matrices', nevertheless, in general, most behavioural expressions are considered to be evoked by the contribution and involvement of all four processing 'matrices'. LeDoux's notion ${ }^{48,49}$ postulates that the neural connections stemming from the emotional circuitry to the cognitive functioning circuitry is more dominant than that extending in the converse direction thereby providing some support for the contention that 'emotions may guide cognitions'. This contention may be central to the present discussion concerning the empowerment model since much may be made about how 'empowerment contingencies' can strengthen the cognitive system so it may selectively and adaptively assume guidance the emotional system under necessary circumstances. Bechara et al. ${ }^{70}$ have provided some support from cases wherein minimal deficits in cognitive ability were accompanied by marked deficits in emotional processing led to both major problems making decisions exacerbated by making the wrong decisions, eventually. Regional brain activity measures can provide indices of both an individual's current emotional 'set-up' [state] ${ }^{71}$, as well as personality characteristics and temperament (ref), thereby offering the propensity to derive assessments of empowerment at functional and regional levels. Empowerment is particularly relevant for the contributions of emotional circuits under normal and/or performance-related conditions where adequate decision-making is a requirement; empowerment, in this case, takes the form of 'adaptively-advantageous' affective judgements (cf. "Self-fulfilling" affective personality), in turn dependent upon suitable somatic and psychological markers. Thus, Bechara et al. ${ }^{72}$ observed that patients with bilateral damage to ventromedial areas of the prefrontal cortex failed to express emotional reactions normally associated with decision-making; it would seem that the necessary brain circuitry required for 'empowerment' was lacking. Further to the requirements of empowerment, patients with right hemisphere prefrontal cortex damage demonstrated less sensitivity for eventual negative consequences (cf. "Self-destructive" affective personality) of their decisions whereas patients with left hemisphere prefrontal cortex damage were less sensitive to possible positive effects (cf. "Low affective" affective personality).

The notion of empowerment ought to be regarded particularly in the context of individuals' locus of control whereby the influence of affective personality appears to be of marked relevance. Locus of control refers to a generalized expectancy of perceived internal or external control through which individuals associate events with their own behaviour or relatively permanent characteristics $^{38,39}$. Individuals assuming that event outcomes are due to their own ability, skills, efforts, and/or characteristics are referred to as possessing an "Internal" locus of control, whereas individuals assuming that event outcomes are due to external forces, such as luck, chance, fate and/or other powerful forces are referred to as possessing an "External" locus of control. According to the notion of locus of control, individuals may be characterised along a spectrum of "highly internal" or "highly external". Millet and Sandberg ${ }^{38}$ have found that individual status regarding locus of control at the start of rehabilitation exerted an important influence upon the outcome of vocational rehabilitation pro- 
grams. Those individuals expressing a predominantly external locus of control attaining a less favourable point of departure at the start of vocational rehabilitation as well as a less favourable outcome for health status, length of sick leave and duration of unemployment. Locus of control orientation ("Internal" versus "External") of small business owners-managers was related to efficacy of management strategies and leadership styles, as well as financial performance ${ }^{38}$. Both Study I and Study II demonstrated that "Self-destructive" individuals expressed a markedly higher external locus of control orientation in comparison with "Self-fulfilling" individuals. Recently, it was indicated that external locus of control predicted NA in a population of 305 high school students ${ }^{73}$. Interestingly, we have found too, in another study of profession workers, that the "Self-fulfilling" individuals expressed significantly higher internal locus of control and selfimage than the "Self-destructive" individuals $^{74}$. Accordingly ${ }^{38}$, an external orientation poses difficulties in creating and utilizing "spaces of action", whereas an internal orientation facilitates the creation and utilization of "spaces of action". Nevertheless, it appears that neither individuals' affective personality ${ }^{75}$ nor locus of control orientation $^{38}$ are necessarily permanent features of personal profiles. The notion of empowerment captures conditions that are arranged to facilitate the development of personal resources through the acquisition of cognitive processes that modulate maladaptive emotional expressions and negative affect. Accordingly, it would appear that the interventional propensities rendered through 'empowerment reinforcement' ought to provide some degree of efficacy for more favourable expressions of both affective personality and locus of control.

\section{References}

1. Gershon ES, Bunney WE Jr, Leckman J, Van Eerdeweg M, DeBauche B. The inheritance of affective disorders: a review of data and hypothesis. Behav Genet 1976; 6: 227-261.

2. Moldin SO, Reich T, Rice JP. Current perspectives on the genetics of unipolar depression. Behav Genet 1991; 21: 211-242.

3. Cohen S. Contrasting the hassle scale and perceived stress scale. Am Psychol 1986; 41: 717-718.

4. Penninx BW, Guralnik JM, Ferruci L, Simonsick EM, Deeg DJ, Wallace RB. Depressive symptoms and physical decline in community-dwelling older persons. JAMA 1998; 279: 1720-1726.

5. Russell JA, Carroll JM. On the bipolarity of positive and negative affect. Psychol Bull 1999; 125: 3-30.

6. Hevey D, McGee HM, Horgan J. Responsiveness of health-related quality of life outcome measures in cardiac rehabilitation: comparison of cardiac rehabilitation measures. J Consult Clin Psychol 2004; 72: 1175-1180.

7. Iacovides A, Fountoulakis KN, Kaprinis S, Kaprinis G. The relationship between job stress, burnout and clinical depression. J Affect Disord 2003; 75: 209-221.

8. Nykli'cek I, Pop VJ. Past and familial depression predict current symptoms of professional burnout. J Affect Disord 2005; 88: 63-68.

9. Aldwin CM. Stress, Coping and Development: an Integrative Perspective. New York; Guilford: 1994.

10. Hirschfeld RM, Klerman GL, Clayton PJ, Keller MB, McDonald-Scott P, Larkin BH. Assessing personality: effects of the depressive state on trait measurement. Am J Psychiat 1983; 140: 695-699.

11. Lauer CJ, Bronisch T, Kainz M, Schreiber W, Holsboer F, Krieg JC. Premorbid psychometric profile of subjects at high familial risk for affective disorder. Psychol Med 1997; 27: 355-362.

12. Almagor M, Ben-Porath Y. The two-factor model of self-reported mood: a cross-cultural replication. J Personal Assess 1989; 53: 10-21.

13. Watson D, Tellegen A. Toward a consensual structure of mood. Psychol Bull 1985; 98: 219-235.

14. Zevon MA, Tellegen A. The structure of mood change: an idiographic/nomothetic analysis. J Person Soc Psychol 1982; 43: 111-122. 
15. Norlander T, Bood SA, Archer T. Performance during stress: Affective personality, age and regularity of physical exercise. Soc Behav Per 2002; 30: 495-508.

16. Watson D, Clark L. Negative affectivity: the disposition to experience aversive negative states. Psychol Bull 1984; 96: 465-490.

17. Watson D, Clark LA, Tellegen A. Development and validation of brief measures of positive and negative affect: the PANAS scales. J Per Soc Psychol 1988; 54: 10631070 .

18. Watson D, Carey LA, Carey G. Positive and negative affectivity and their relation to anxiety and depressive disorders. J Abnorm Psychol 1988; 97: 346-353.

19. Park CL, Cohen LH, Murch R. Assessment and prediction of stress-related growth. J Per 1996; 64: 71-105.

20. Melvin GA, Molly GN. Some psychometric properties of the Positive and Negative Affect Schedule among Australian youth. Psychol Rep 2000; 86: 1209-1212.

21. Watson D, Pennebaker JW and Folger R. Beyond negative affectivity: measuring stress and satisfaction in the workplace. J Organ Behav Manage 1987; 8: 141-157.

22. Karlsson E, Archer T. Relationship between Personality Characteristics and Affect: Gender and Affective Personality. Individ Diff Res 2007; in press.

23. George JM, Brief AP. Feeling good-doing good: A conceptual analysis of the mood at work-organizational spontaneity relationship. Psychol Bull 1992; 112(2): 310-329.

24. Isen AM, Levin PF. Effect of feeling good on helping: cookies and kindness. J Per Soc Psychol 1972; 21: 384388 .

25. McCrae RR, Costa PT Jr. Validation of the five-factor model of personality across instruments and observers. J Per Soc Psychol 1987; 1: 81-90.

26. Costa PTJ, McCrae RR. Influence of extroversion and neuroticism on subjective well-being: happy and unhappy people. J Per Soc Psychol 1980; 38: 668-687.

27. Varg N. [The influence of negative affect upon responses to questionnaires]. Stockholm: Stockholm Univeristy Reports: 1997.

28. Watson D, Clark LA. The PANAS-X, Manual for the Positive and Negative Affect Schedule - Expanded form. Iowa. The University of Iowa reports copyright, 1994; pp 1-24.

29. Spector PE, O'Connell BJ. The contribution of personality traits, negative affectivity, locus of control and Type A to the subsequent reports of job stressors and job strains. J Occup Organ Psychol 1994; 67: 1-11.
30. Ashby FG, Isen AM, Turken AU. A neuropsychological theory of positive affect and its influence on cognition. Psychol Rev 1999; 106: 529-550.

31. Wilson K, Gullone E, Moss S. The youth version of the positive and negative affect schedule. Behav Change 1998; 15: 187-193.

32. Gray JR, Burgess GC, Schaefer A, Yarkoni T, Larsen RJ, Braver TS. Affective personality differences in neural processing efficiency confirmed using fMRI. Cog Affect Behav Neurosci 2005; 5(2): 182-190.

33. Palomo T, Beninger RJ, Kostrzewa RM, Archer T. Gene-environment interplay in affect and dementia: Emotional modulation of cognitive expression in personal outcome. Neurotox Res 2004; 6: 159-173.

34. Agerström J, Moller K, Archer T. Influence of affective personality and dilemma content on moral reasoning: effect of gender. Social Behav Personal 2006; 34: 12591276.

35. Bood SA, Archer T, Norlander T. Affective personality in relation to general personality, self-reported stress, coping and optimism. Individ Diff Res 2004; 2: 26-37.

36. Kjellberg A, Iwanovski S. [Stress/Energy-questionnaire: development of a method for estimation of mood in worklife]. Solna: Arbetsmiljöinstitutet; 1989.

37. Norlander T, Archer T. Predicting performance in ski and swim championships: effectiveness of mood, perceived exertion, and dispositional optimism. Percept Mot Skills 2002; 94: 153-164.

38. Millet P, Sandberg K. Locus of control and its relationship with rehabilitation outcomes of unemployed sick leavers in Sweden. J Vocat Rehab 2003; 19: 59-66.

39. Rotter JB. Generalized expectancies for Internal versus External Control of Locus of Reinforcement. Psychol Monogr 1966; 80 (Whole no. 609).

40. Erbin-Roesemann MA, Simms L. Work locus of control: the intrinsic factor behind empowerment and work excitement. Nurs Econ 1997; 15: 183-190.

41. Beck AT, Ward CH, Mendelson M, Mock J, Erbaugh J. An inventory for measuring depression. Arch Gen Psychiatry $1961 ; 4: 561-571$.

42. Beck AT, Steer RA, Garbin MG. Psychometric properties of the Beck Depression Inventory: twenty-five years of evaluation. Clin Psychol Rev 1988; 8: 77-100.

43. Foa E, Riggs B, Dancu CVS, Rothbaum BO. Reliability and validity of a brief instrument for assessing Post Traumatic Stress Disorder. J Traumat Stress 1993; 6: 459-473. 
44. Flett GL, Hewitt PL. Perfectionism: Theory, research and treatment. Washington, DC: American Psychological Association: 2002.

45. Herrmann C. International experiences with hospital anxiety and depression scales - a review validating data and clinical results. J Psychosom Res 1997; 11: 213-218.

46. Hetta J, Almqvist M, Agren H, Hambert G, Liljenberg GB, Roos BE. Prevalence of sleep disturbances and related symptoms in a middle-aged Swedish population. In: WP Koella, E Ruther and H Schultz (Eds.), Sleep '84. Stuttgart: Gustaf Fischer Förlag, 1985: pp. 373-376.

47. Seigel K, Broman J-E, Hetta J. Behavioral activation or inhibition during emotional stress - implications for exercise habits and emotional problems among young females. Nord J Psychiat 2002; 56: 441-446.

48. LeDoux JE. Emotional memory systems in the brain. Behav Brain Res 1993; 58: 69-79.

49. LeDoux JE. Emotion: Clues from the Brain. Ann Rev Psychol 1995; 46: 209-235.

50. Gross JJ. Emotion regulation: affective, cognitive, and social consequences. Psychophysiol 2002; 39: 281-291.

51. Amaral DG, Behniea H, Kelly JL. Topographic organization of projections from the amygdala to the visual cortex in the macaque monkey. Neuroscience 2003; 118: 1099-1120.

52. Phelps EA. Emotion and cognition: insights from studies of the human amygdala. Ann Rev Psychol 2006; 57: 27-53.

53. Gray JR. Integration of emotion and cognitive control. Curr Direc Psychol Sci 2004; 13: 46-48.

54. Gray JR, Braver TS, Raichle ME. Integration of emotion and cognition in the lateral prefrontal cortex. Proc Nat Acad Sci U S A 2002; 99: 4115-4120.

55. Oaksford M, Morris F, Grainger B, Williams JMG. Mood, reasoning, and central executive processes. J Exp Psychol: Learn Mem Cogn 1996; 22: 477-493.

56. Phillips LH, Bull R, Adams E, Fraser L. Positive mood and executive function: evidence from Stroop and fluency tasks. Emotion 2002; 2: 21-22.

57. Vosburg SK. The effect of positive and negative mood on divergent-thinking performance. Creativity Res J 1998; 11: 165-172.

58. Davidson RJ, Shackman AJ, Maxwell JS. Asymmetries in face and brain related to emotion. Trends Cogn Sci 2004; 8: 389-391.

59. Beats B, Sahakian B, Levy R. Cognitive performance in tests sensitive to frontal lobe dysfunction in the elderly depressed. Psychol Med 1996; 26: 591-603.
60. Tarbuck A, Paykel E. Effects of major depression on the cognitive function of younger and older subjects. Psychol Med 1995; 25: 285-296.

61. Kizilbash A, Vanderploeg R, Curtiss G. The effects of depression and anxiety on memory performance. Arch Clin Neuropsychol 2002; 17: 57-67.

62. Biringer E, Mykletun A, Dahl AA, Smith AD, Engedal K, Nygaard HA, Lund A. The association between depression, anxiety, and cognitive function in the elderly general population - the Hordaland health study. Int. J Geriatr Psychiatry 2005; 20: 989-997.

63. Weis D, Schank MJ, Matheus R. The process of empowerment: a parish nurse perspective. J Holistic Nursing 2006; 24: 17-24.

64. World Health Organisation. WHO primary health care: Report of the International Conference on Primary Health Care, Alma Ata, USSR (WHO Health for all, Set No. 1). Geneva, WHO: 1978.

65. Goodley D. Empowerment, self-advocacy and resilience. J Intellect Disabil 2005; 9: 333-343.

66. Rusch N, Lieb K, Bohus M, Corrigan PW. Brief reports: self-stigma, empowerment, and perceived legitamy of discrimination among women with mental illness. Psychiatr Serv 2006; 57: 399-402.

67. Yeung RR, Hemsley DR. Personality, exercise and psychological well-being. Pers Individ Dif 1997; 22: 4753.

68. Gasper K. Do you see what I see? Affect and visual information processing. Cogn Emotion 2004; 18: 405-421.

69. Camerer C, Loewenstein G, Prelec D. Neuroeconomics: how neuroscience can inform economics. Unpublished manuscript; 2004.

70. Bechara A, Damasio H, Damasio AR. Emotion, decision-making, and the orbitofrontal cortex. Cereb Cortex 2000; 10: 295-307.

71. Damasio AR, Grabowski TJ, Bechara A, Damasio H, Ponto LLB, Parvizi J. Hichwa RD. Subcortical and cortical brain activity during the feeling of self-generated emotions. Nat Neurosci 2000; 3: 1049-1056.

72. Bechara A, Bertolino MV, Casabé A, Fredotovich N. A Double-Blind Randomized Placebo Control Study Comparing the Objective and Subjective Changes in Female Sexual Response Using Sublingual Apomorphine. J Sex Med 2004; 1(2): 209-214.

73. Palomo T, Beninger RJ, Kostrzewa RM, Archer T. Treatment consideration and manifest complexity in comorbid neuropsychiatric disorders. Neurotox Res 2007; 12: 1-18. 
74. Archer T, Adolfsson B, Karlsson E. Affective personality as cognitive-emotional presymptom profiles regulatory for self-reported health predispositions. Submitted.

75. Jansson L, Archer T, Norlander T. Achievement of timing at the highest competitive level: the necessity of a ‘driving conviction'. Athletic Insight 2005; 7: 37-49.
Address for correspondence: Trevor Archer University of Göteborg Dep. of Psychology Box 500 SE-405 30 Göteborg. SWEDEN

E-mail: trevor.archer@psy.gu.se 